\title{
Some Aspects on the Variability of the Satellitized Arm, in Human Acrocentric Chromosomes
}

\author{
C. de la Torre and G. Giménez-Martín \\ Instituto de Biología Celular, C.S.I.C., Velázquez, 144. Madrid-6, Spain
}

Received December 22, 1970

The five pairs of acrocentric chromosomes in the human complement (groups $\mathrm{D}$ and $\mathrm{C}$ ) have a heterochromatic zone or secondary constriction between the centromere and the distal part of the shorter arm, which Ohno et al. (1961) characterized as the region where the nucleolus is organized. Fergusson-Smith and Handmaker (1961) drew attention to the presence of satellites in all of them. The nucleolar organizer is a region which is hyperactive in RNA synthesis (Jain et al. 1969) and it is here that the synthesis of ribosomal RNA takes place (Ritossa and Spiegelman 1965, Brinstiel et al. 1966).

In view of the variability observed in these short arms, it has been considered important to study its possible causes.

\section{Material and methods}

100 metaphases were chosen from 136 phenotypically normal men and women. The culture of lymphocytes were made according to the technique of Moorhead et al. (1960) with slight modifications: 30 minutes colchicine at $0.0002 \%$ and hypotonic pretreatment with $3: 1$ distilled water and were arrested at the 72 hours. The preparatory technique was maintained in every case as nearly identical as possible, to avoid the variation observed in the number of satellites attributable to the technique (Henneen and Nichols 1966, Ford and Woollan 1967, Zang and Bang 1968 and Nankin 1970). The metaphases were chosen in consideration of the elongation of most of the chromosomes, those in which the centromere of either acrocentric chromosome was not easy to discern being eliminated. The measurements were taken with a millimetre ruler on suitable magnified microphotographs.

\section{Observations and discussion}

Variability of the chromatic zone

The relative length of the shorter arm was measured as compared with that of the whole chromosome, not counting the heterochromatic area, and the percentages, by groups, are given in Table I.

Taking the sample by groups, we find that only two of the 136 individuals $(1.5 \%)$ show values in group D statistically different from the norm. Neither of our two cases recalls parental blood relationship.

Case 1.-A phenotypically normal man with 2 of his $6 \mathrm{D}$ chromosomes larger 
Table 1.

\begin{tabular}{c|c|c}
\hline \hline $\begin{array}{c}\text { Chromosome } \\
\text { group }\end{array}$ & $\begin{array}{c}\text { Length of chromatic zone } \\
\text { /total length }\end{array}$ & Standard deviation \\
\hline D & $17.1 \%$ & 1.9 \\
G & $28.3 \%$ & 3.1 \\
D-G & $19.9 \%$ & 2.3 \\
\hline
\end{tabular}
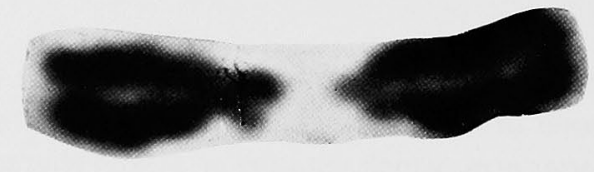

a

b
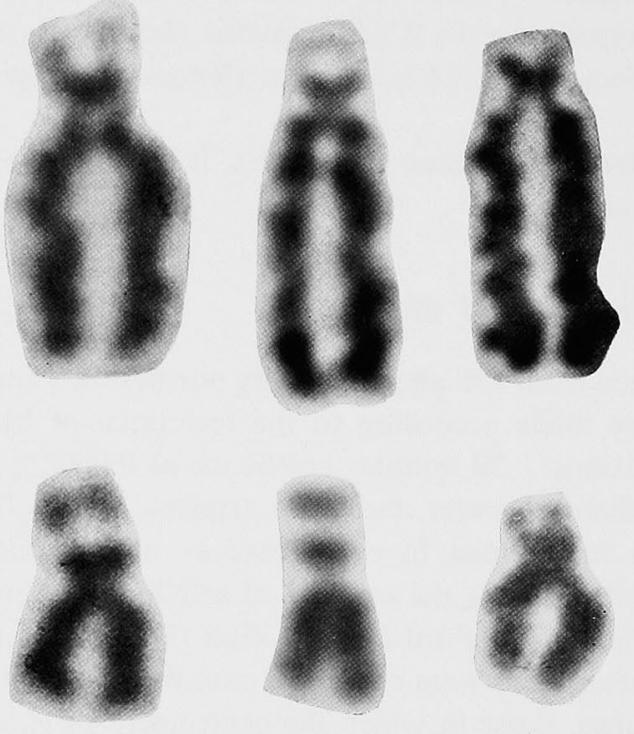

C

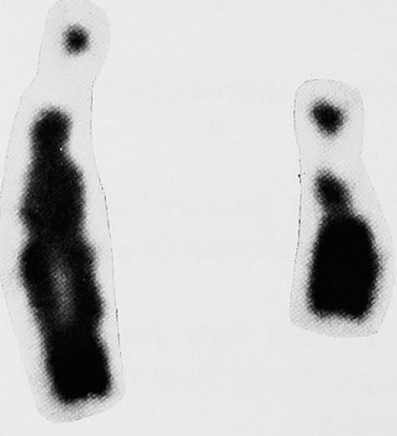

Fig. 1. than the average. Other members were not accessible to chromosome study.

Case 2.-A normal woman, mother of a child affected with mongolism by Robertsonian translocation 46, XY, D - t $(\mathrm{DqGq})+$. Her karyotype proved to be quite normal, but three of her D chromsome showed a chromatin zone in the shorter arms which was larger than the average, and a fourth D chromosome, also, had apparently lost the short arm. Fig. 1 a, shows two of the chromsomes with values departing considerably from the average.

The presence of more than one chromosome with an anomalous relative length of this area might indicate that the area was formed by self-duplication or by chromosomal interaction (Lejeune 1963).

The absence of special phenotypic features in both cases suggests that the studied area must be genetically rather inactive. There are reports of genes affecting the foetal haemoglobin in segments near the centromere of the group D chromosomes 
(Bloom and Gerald 1968) and monosomia has also been reported in the segment of a D chromosome under study, associated with a variety of unspecific phenotypic anomalies (Emerit et al. 1968).

These anomalous values found in the mother might be connected with the Robertsonian translocation, but we must bear in mind that this chromosomal feature might have been inherited an unknown number of times without producing any phenotypic effect.

Variability of the heterochromatic zone

The secondary constriction can be visible-and the chromosome is called "satellited"- - or no. This variability (Fig. 1b) was studied by counting the number of satellitized acrocentric chromosomes per metaphase, and the results of the study are shown in the Table 2.

Table 2 .

\begin{tabular}{c|c}
\hline Number of satellites & Number of metaphases \\
\hline 0 & 11 \\
1 & 78 \\
2 & 183 \\
3 & 265 \\
4 & 326 \\
5 & 98 \\
6 & 32 \\
7 & 4 \\
8 & 2 \\
9 & 1 \\
10 & 0 \\
\hline
\end{tabular}

In order to ascertatin which factors influence on the variability of the length of these heterochromatic zones, we studied them: a) in prometaphase chromosomes, and b) in groups of acrocentric chromosomes taking part in the so-called "satellite association", and chromosomes not taking part in it.

The heterochromatic zones of prometaphase chromosomes were observed to be much more elongated than in the metaphase ones (Fig. $1 \mathrm{c}$ ), but with marked differences in length between one chromosome and another. There seems to be the same proportion in variability as in the metaphase cells of the same individual.

The study of the heterochromatic regions of 500 associated chromosomes gives us a high frequency of visible heterochromatic zones $(78 \%)$, while that of another group of unassociated chromosomes shows a lower frequency of visible heterochromatic regions $(43 \%$ ). Heneen and Nichols (1966) and Nankin (1970) determined that the groups of acrocentric chromosomes observed in the metaphase are the result of chromosomal association in the interphase for the organization of common nucleoli.

Thus, this difference of visibility between the groups studied might be interpreted as reflecting actual differences in functional activity during the interphase, when 
the nucleoli were being organized by the chromosomes which we analysed.

Notwithstanding, we cannot dismissed some variability owed to technical effects, despite our efforts in keeping the preparatory technique as nearly identical as possible, in every case.

\section{Summary}

The variability of chromatic and heterochromatic zones in human acrocentric chromosomes is studied. There is a small variability in the latter, and that of heterochromatic zones seems positively related to the participation of the chromosome in the so-called "satellited association".

\section{References}

Birnstile, M. L., Wallace, H., Sirlin, J. L. and Fischberg, M. 1966. Localization of the ribosomal DNA complements in the nucleolar organizer region of Xenopus laevis. Natl. Cancer Inst. Monograph 23: 431-448.

Bloom, G. E. and Gerald, P. S. 1968. Localization of genes on chromosome 13: analysis of two kindreds. Amer. J. Hum. Genet. 20: 495-511.

Emerit, J., de Grouchy, J. and German, J. 1968. Deletion of the short arm of a chromosome 13. Ann. Génét. 11: 184-186.

Ferguson-Smith, M. A. and Handmaker, S. D. 1961. Observations on the satellited human chromosomes. Lancet 1: 638-641.

Ford, E. and Woollam, D. 1967. Significance of variation in satellite incidence in normal human mitotic chromosomes. Lancet 2: 26-27.

Heneen, W. K. and Nichols, W. W. 1966. Persistence of nucleoli in short term and long term cell cultures and indirect bone marrow preparations in mammalian materials. J. Cell. Biol. 31: 543-561.

Jain, H. K., Raut, R. N. and Nerwal, S. K. 1969. Nucleolar organiser as a hyperactive locus for RNA synthesis. Heredity 24: 59-67.

Lejeune, J. 1963. Origin and significance of autosomal abnormalities. In Genetics Today Symposium 22. Pergamon Press, Oxford.

Moorhead, P. S., Nowell, P. C., Mellman, W. J., Battips, D. M. and Hungerford, D. A. 1960. Chromosome preparations of leukocytes cultured from human peripheral blood. Exptl. Cell Res. 20: 613-616.

Nankin, H. R. 1970. "In vitro" alteration of satellite association and nucleolar persistence in mitotic human lymphocytes. Cytogenetics 9: 42-51.

Ohno, S., Trujillo, J. M., Kaplan, W. D. and Kinosita, R. 1961. Nucleolus organizers in the causation of chromosomal anomalies in man. Lancet 2 : 123-126.

Ritossa, F. M. and Spiegelman, S. 1965. Localization of DNA complementary to ribosomal RNA in the nucleolus organizer region of Drosophila melanogaster. Proc. Natl. Acad. Sci. U.S. 53: 737-745.

Zang, K. D. and Back, E. 1968. Quantitative studies on the arrangement of human metaphase chromosomes. Cytogenetics 7: 455-470. 